\title{
Saphenous neuritis treatment with a single shot femoral block. A case report.
}

\author{
E.Antonopoulou1 1 A. Florou11. V. Polizoidou I. Pazis² .I Papavasileiou²
}

${ }^{1}$ Anaesthetic Department ${ }^{2}$ Orthopedic Department General Hospital of Xanthi Greece

\section{Background and aims. Saphenous neuropathy due to saphenectomy treated well with a femoral nerve block.}

Methods. A 65-year-old woman overweight with type II diabetes mellitus and coronary artery disease underwent surgery to replace 4 coronary arteries with grafts derived from the saphenous vein. Two months later, she complains of intense pain on the inner surface of the thigh with a VAS score of 8-9. Saphenous nerve neuralgia occurs due to nerve injury. It is a potential complication of greater saphenous vein stripping. We decided to block the femoral nerve using an $\mathrm{U} / \mathrm{S}$ with a bolus dose of $10 \mathrm{ml}$ Ropivacaine $2 \mathrm{mg} / \mathrm{ml}$. The patient was fully recovered from pain symptoms ten minutes later. Eight weeks later she is still free of pain.

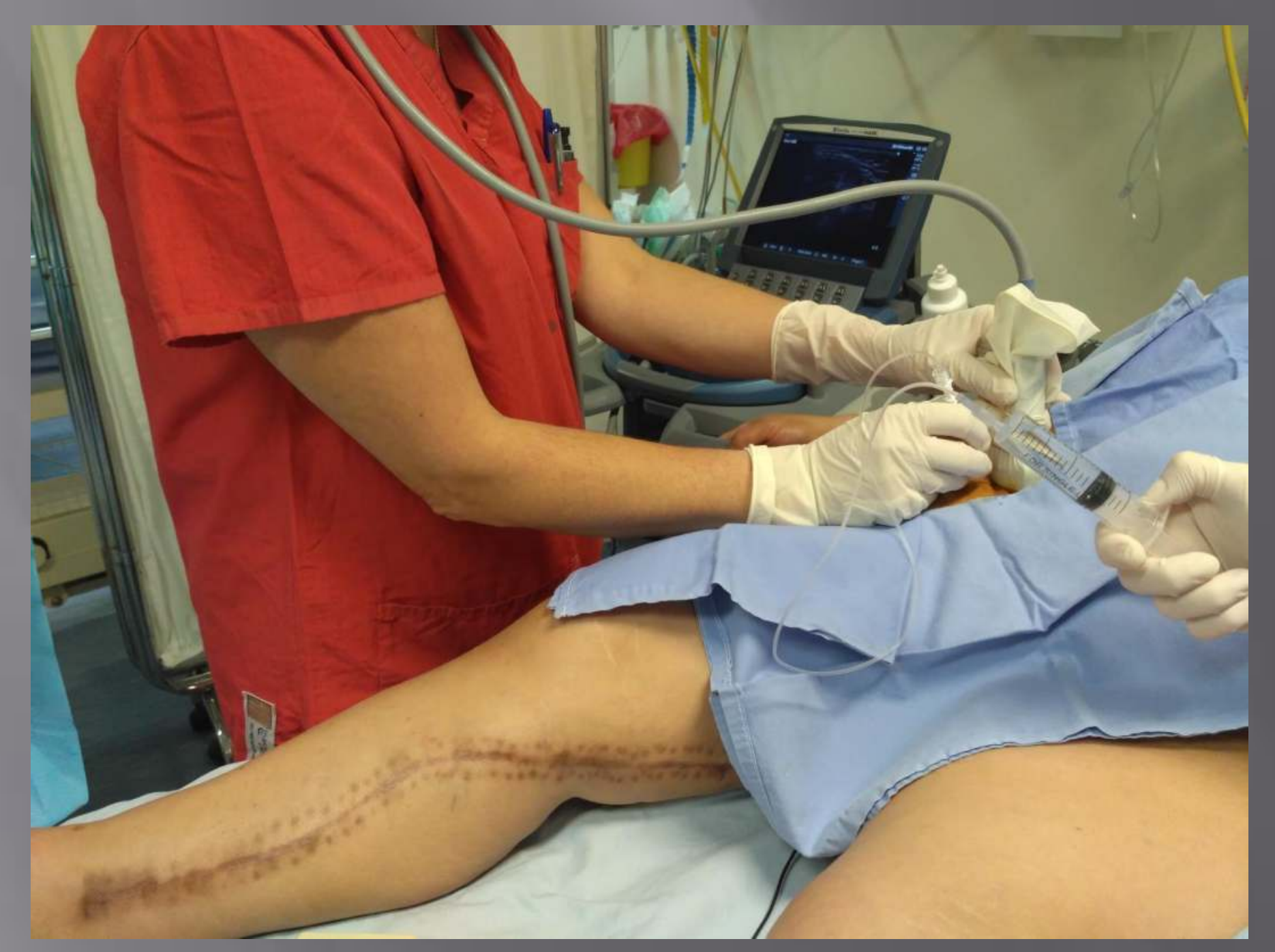

Conclusions. Saphenous nerve injury is quite rare during saphenectomy and difficult to recognize although it is well treated with a single shot femoral nerve block. 